\title{
Coumaphos affects food transfer between workers of honeybee Apis mellifera
}

\author{
Danilo Bevk, Jasna KralJ, Andrej ČoKL \\ National Institute of Biology, Večna pot 111, 1000 Ljubljana, Slovenia
}

Received 8 June 2011 - Revised 9 November 2011 - Accepted 23 November 2011

\begin{abstract}
We investigated whether coumaphos, an organophosphate used to control the parasitic mite Varroa destructor, affects trophallaxis in honeybees. Donors were treated with coumaphos $1 \mathrm{~h}$ before experiments. In this, uncontaminated food was transferred from donors to recipients. The amount of food transferred was measured (a) directly by weighing food or (b) indirectly by the number of recipients that died due to insufficient trophallaxis. A large reduction in the amount of transferred food was observed when the donors received $5 \mu \mathrm{g}$ of coumaphos $1 \mathrm{~h}$ prior to the experiment. High mortality was observed among the recipients that were fed by donors treated with 2 or $5 \mu \mathrm{g}$ of coumaphos indicating insufficient food transfer. Demonstrated side effects of coumaphos on trophallaxis could reduce distribution of this systemic agent in the colony and decreases its efficacy. The described assays are feasible and could be a useful tool to test the effects of pesticides on trophallaxis.
\end{abstract}

Apis mellifera / coumaphos / trophallaxis / social behaviour / food

\section{INTRODUCTION}

Coumaphos is an organophosphate with acaricidic properties and systemic action. It is the active ingredient of Perizin ${ }^{\circledR}$ (Bayer, $32 \mathrm{mg} / \mathrm{mL}$ ), which is widely used to control the parasitic mite Varroa destructor. One millilitre of Perizin solution diluted in $49 \mathrm{~mL}$ water is trickled over bees in the late autumn or winter, ideally in broodless conditions. Two treatments 1 week apart are recommended.

Perizin consumed by bees is spread by social feeding within honeybee colonies. However, this is a minor part of the distribution, since only about one fourth of the applied coumaphos is ingested by the bees. The main part is distributed externally by contact via comb cleaning and self and nest mate grooming (van

Corresponding author: D. Bevk, danilo.bevk@gmail.com

Manuscript editor: Marla Spivak
Buren et al. 1992a). Perizin is distributed among the bees in a colony within $3 \mathrm{~h}$ of application (van Buren et al. 1993).

Active ingestion of coumaphos solution can result in high concentrations in the alimentary track, which then decrease rapidly by metabolism and excretion (van Buren et al. 1992b; Tremolada et al. 2004). A maximum of about $3 \%$ of the amount ingested is transferred to the haemolymph (van Buren et al. 1992b) and causes the death of mites that feed on haemolymph (van Buren et al. 1992a) by irreversible inhibition of acetylcholinesterase activity (Menozzi et al. 2004).

Coumaphos exerts negative effects on bees. The acute lethal dose $\left(\mathrm{LD}_{50}\right)$ of coumaphos is age dependent (3 to $6 \mu \mathrm{g}$ ), being lower in older bees (van Buren et al. 1992b). Negative effects have also been observed with lower, sublethal acute doses. Queens in colonies treated with coumaphos-impregnated strips weigh significantly less, have lower ovary weights and show 
atypical behaviour, and the queen pupae suffer a high mortality rate (Haarmann et al. 2002). In workers, coumaphos reduces foraging activity (Schneider et al. 2009), affects the hypopharyngeal acinus diameter and triggers an increased level of programmed cell death (Smodiš Škerl and Gregorc 2010). Residues in wax can also affect queens' health adversely (Collins et al. 2004; Pettis et al. 2004).

So far, no effects on social behaviour have been reported. In this study, we investigated whether coumaphos in sublethal doses affects trophallaxis and consequently influences transmission of acaricide within the honeybee colony. For this purpose, we designed a direct and indirect method to estimate the amount of food transferred from the donor to recipient bees.

\section{MATERIALS AND METHODS}

\subsection{Preparation of experiments}

The experiments were carried out in June and July 2009 using caged bees from colonies of Apis mellifera carnica Polm. Because food transfer depends on age (Free 1957; Moritz and Hallemen 1986; Crailsheim 1998), we used donor bees of the same age at which trophallaxis is effectively performed (11-21 days). Six hundred to 1,000 one-day-old bees from several colonies were marked every week with different colours and introduced into two colonies, each accommodating five frames. Marked bees were retrieved from the colony at a minimum age of 11 days. After starving for $1 \mathrm{~h}$, donor bees were fed individually in modified queen marking tubes with $10 \mu \mathrm{L} 30 \%$ sugar solution spiked with different doses of coumaphos (1,2 and $5 \mu \mathrm{g}$ ) or containing no coumaphos as a control. Sugar solution instead of water was used to make the Perizin more attractive for bees to consume. All solutions were prepared daily. Bees that did not take all the offered solution in $15 \mathrm{~min}$ were excluded from the experiment.

Recipients were bees of unknown age leaving the colony that were captured at the entrance of the same hive occupied by the donors. They were immediately used in the experiments after they had been collected. As recipients were without food supply in the assays and they were completely dependent on receiving food from the donors.

\subsection{Experiment 1: the amount of food transferred from a donor bee to recipient bees}

Experimental cages for donor bees were modified plastic $20 \mathrm{~mL}$ Rotilabo ${ }^{\circledR}$ containers (31 mm diameter $\times$ $43 \mathrm{~mm}$ long). An opening of $25 \mathrm{~mm}$ diameter was made in the lid of the container and covered with a metal screen $(3 \times 3 \mathrm{~mm}$ mesh $)$ that allowed trophallaxis between the donor bee inside and recipient bees outside the cage (Figure 1). The cages were equipped with a feeder containing a weighed $2 \mathrm{~mL}$ of $20 \%$ sugar solution. The feeder was a modified 6-mL syringe. Half of the tip was cut longitudinally to allow the bee to reach the barrel with its proboscis.

In each experiment, four cages, each with a single donor bee that had received 1,2 or $5 \mu \mathrm{g}$ of coumaphos or only pure sugar solution prior to the experiment, were

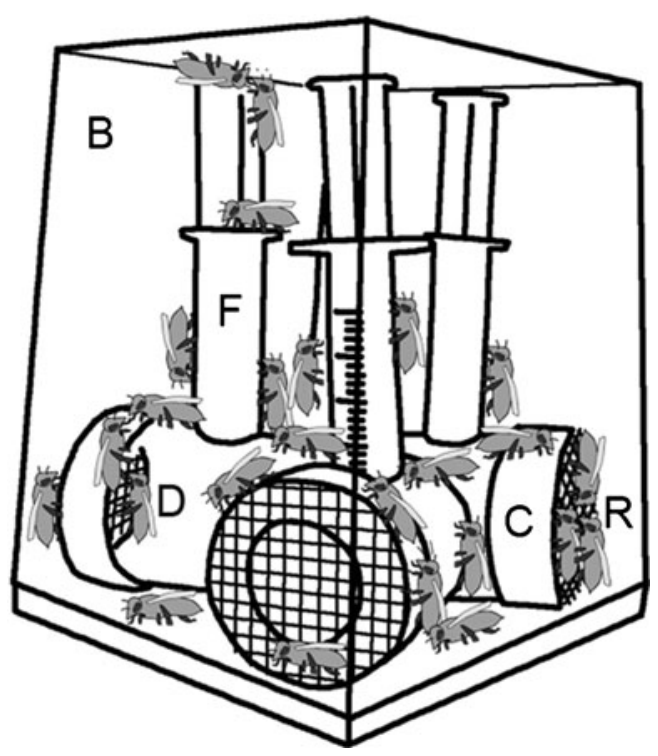

Figure 1. Schematic of experiment 1. The amount of food transferred from a donor to recipient bees. The difference in the weight of food in a feeder at the beginning and at the end of the experiment was measured to estimate the efficacy of food transfer between a donor and recipient bees. $B 1,000-\mathrm{ml}$ box, $C$ 20-ml cage (four in one box), $D$ donor bee (one inside each cage), $R$ recipient bees (30 outside the cage), $F$ feeder with sugar solution. Cages in the box were not interconnected. 
placed together in a 1,000-mL plastic box (Figure 1). Each cage was supplied with uncontaminated sugar solution. Thirty recipient bees were added to the box after a time interval of $1 \mathrm{~h}$. As main part of crop volume is used up by the bees within $1 \mathrm{~h}$ (Crailsheim 1988), it thus can be assumed that no coumaphos is transferred from donors to recipients after this time. The boxes were placed into an incubator $\left(34^{\circ} \mathrm{C}\right.$, darkness). After $24 \mathrm{~h}$, the amount of food removed from the feeders was measured by weighing the feeders again.

The amount of transferred food for each single donor was calculated as the difference between the weight of the feeder before and after experiment. For each dose, 51 donor bees were tested at an average age of 13 days (range from 11 to 15 days).

To assure that differences in weight were mainly the result of food transfer between donor and recipient bees, we determined the loss of sugar solution due to intake of donors and evaporation. A single worker was placed in the cage $1 \mathrm{~h}$ after feeding with $10 \mu \mathrm{L}$ of control solution, with the feeder containing a weighed $2 \mathrm{~mL}$ of $20 \%$ sugar solution. The cages were placed into an incubator $\left(34^{\circ} \mathrm{C}\right.$, darkness). After $24 \mathrm{~h}$, the feeders were weighed again. We tested 30 bees.

\subsection{Experiment 2: mortality of recipient bees}

As an indirect way to determine trophallaxis, the ability of donor bees to supply recipients with food was measured by mortality of recipients. A single donor bee was placed in a plastic cage made of two 20-mL Rotilabo ${ }^{\circledR}$ containers separated by a metal screen (Figure 2). One side contained the donor bee and was provided with a feeder containing $2 \mathrm{~mL}$ of $20 \%$ sugar solution. On the other side of the mesh, ten recipient bees were added $1 \mathrm{~h}$ after the donor bee had been treated with sugar solution with or without coumaphos. One hour time delay was used to prevent transfer of coumaphos from donors to recipients. The cages were then placed in the incubator $\left(34^{\circ} \mathrm{C}\right.$, darkness). After 4 and $24 \mathrm{~h}$, the number of dead recipients was counted. For each dose, 51 donor bees were tested at an average age of 16 days (range from 12 to 21 days). If a donor bee died, the trial was excluded.

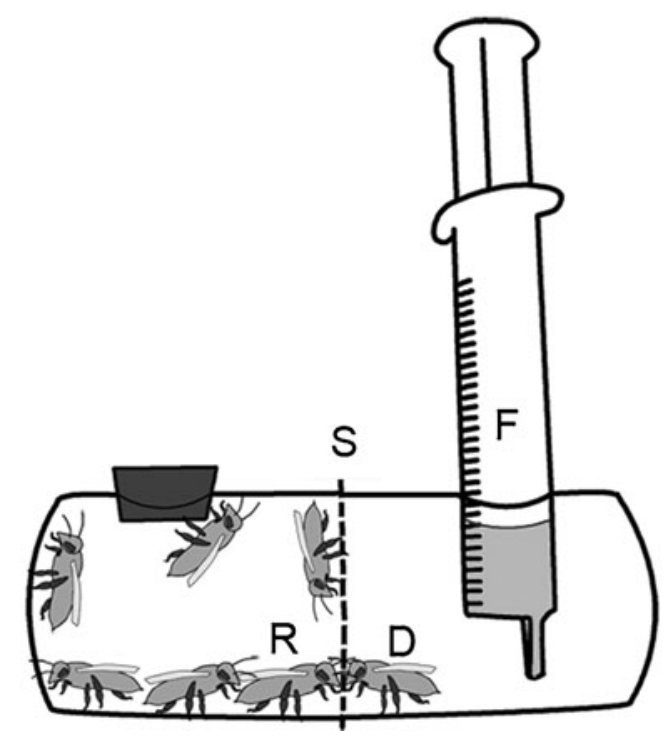

Figure 2. Schematic of experiment 2. Mortality of recipient bees. Survival of recipient bees was a measure of successful food transfer between a donor and recipient bees. $D$ donor bee, $R$ recipient bees, $F$ feeder with sugar solution, $S$ metal screen.

\section{RESULTS}

\subsection{Experiment 1: the amount of food transferred from a donor to recipient bees}

The average food removal from the feeders due to food consumption by the donor and evaporation in $24 \mathrm{~h}$ was $100.63 \mathrm{mg}$ (with a range of 82 to $123 \mathrm{mg}$ ). The average food removal in the experiment of food transfer by untreated donors to recipients was $688.69 \mathrm{mg}$ (range 220 to $1,510 \mathrm{mg}$ ), which is approximately seven times higher than food removal due to food intake and evaporation by the donor alone. This indicates that the differences in weight before and after the experiment were mainly the result of food transfer between the donor and recipient bees. Total food removal was thus regarded as a good approximation of food transfer.

Food intake by a single donor bee and by a group of four donor bees over $24 \mathrm{~h}$ ranged from 40 to $1,620 \mathrm{mg}$ and from 840 to 3,420 $\mathrm{mg}$ of sugar solution, respectively. To remove the influence of 
variation in total food removal between experiments, food transfer was expressed as a percentage of the total transfer from each of the four donor bees in the box. Transfer of uncontaminated sugar solution between donors and recipients decreased with the increase of coumaphos dose that donors had received prior to the experiment (Spearman correlation, $r=-0.386, n=204, P<$ 0.01 , Figure 3). In particular, the median transfer from bees that had received $5 \mu \mathrm{g}$ of coumaphos was $18 \%$ of total food transferred in one experiment which is 1.6 times less than in the controls $(28 \%)$. The difference was highly significant $(P<0.001$, Mann-Whitney $U$ test $)$. Transfer of uncontaminated sugar solution by bees that had received $2 \mu \mathrm{g}$ of coumaphos was also lower than in the controls $(24 \%)$ but the difference was not significant. Treatment with $1 \mu \mathrm{g}$ did not reduce food transfer between the donor and recipient bees.

\subsection{Experiment 2: mortality of recipient bees}

The mortality of recipient bees increased with the amount of coumaphos that the donors had received $1 \mathrm{~h}$ before the experiment. The correlation between coumaphos treatment of donor bees and mortality of recipient bees was positive and highly significant at 4 and at $24 \mathrm{~h}$ after the recipients had been added to the donors (Spearman correlation, $4 \mathrm{~h}, r=0.509, n=200, P<$ $0.01 ; 24 \mathrm{~h}, r=0.424, n=200, P<0.01)$. The mortality of recipient bees interacting with $5 \mu \mathrm{g}$-fed donor bees was 7.7 and 3.4 times higher than in the controls at $4 \mathrm{~h}$ and at $24 \mathrm{~h}$, respectively $\left(4 \mathrm{~h}, \chi^{2}=237.02, P<0.001 ; 24 \mathrm{~h}\right.$, $\chi^{2}=207.73, P<0.001$, Table I). Similarly, the mortality of recipient bees from $2 \mu \mathrm{g}$-fed donor bees was 1.6 times higher than controls after $4 \mathrm{~h}$ $\left(\chi^{2}=5.55, P<0.05\right)$, but there was no difference after $24 \mathrm{~h}$. No difference in mortality was found between recipients dependent on donors fed with $1 \mu \mathrm{g}$ and those in the control group.

\section{DISCUSSION}

The overall results demonstrate that treatment with a sublethal dose of coumaphos reduces the amount of trophallaxis by honeybees and thus could interfere with food distribution within the honeybee colony. This effect is dose dependent. Donor bees treated with the highest dose of $5 \mu \mathrm{g}$ coumaphos $1 \mathrm{~h}$ prior to the experiment

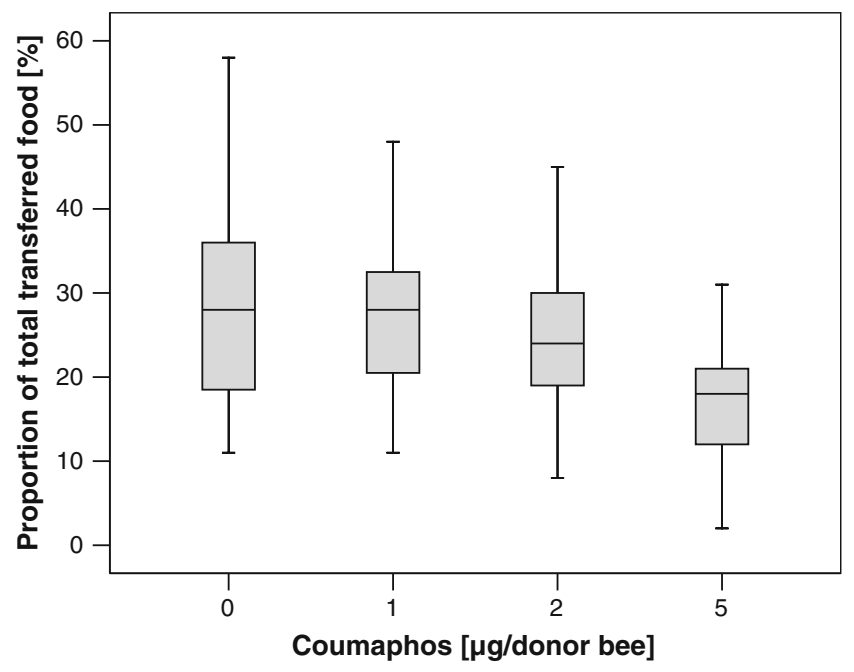

Figure 3. The amount of food transferred from coumaphos-treated donor bees. The food transfer for each donor is expressed as the proportion of total food removed by four donors in one experiment ( $N$ donors $=204, N$ experiments $=51$ ). The chart indicates medians, interquartile ranges, $10 \%$ and $90 \%$ percentiles. 
Table I. The number and percentage of dead recipient bees 4 and $24 \mathrm{~h}$ after they had been added to the donors.

\begin{tabular}{|c|c|c|c|c|c|}
\hline \multirow{2}{*}{$\begin{array}{l}\text { Coumaphos } \\
\text { ( } \mu \mathrm{g} / \text { donor })\end{array}$} & \multirow[t]{2}{*}{$N$ (recipient bees) } & \multicolumn{2}{|l|}{$4 \mathrm{~h}$} & \multicolumn{2}{|l|}{$24 \mathrm{~h}$} \\
\hline & & $\begin{array}{l}N \text { (dead } \\
\text { recipients) }\end{array}$ & $\begin{array}{l}\%(\text { dead } \\
\text { recipients })\end{array}$ & $\begin{array}{l}N \text { (dead } \\
\text { recipients) }\end{array}$ & $\begin{array}{l}\%(\text { dead } \\
\text { recipients })\end{array}$ \\
\hline 0 & 500 & 33 & 6.7 & 92 & 18.4 \\
\hline 1 & 500 & 41 & 8.2 & 84 & 16.8 \\
\hline 2 & 500 & 54 & 10.8 & 104 & 20.8 \\
\hline 5 & 500 & 253 & 50.6 & 316 & 63.2 \\
\hline
\end{tabular}

Ten recipient bees were fed by one donor. The number of dead bees after $24 \mathrm{~h}$ is cumulative

transferred almost two times less sugar solution to the recipients compared to untreated donors.

Similar results were obtained by counting dead recipient bees resulting from insufficient food transfer between the donor and recipient bees. Mortality increased with the amount of coumaphos treatment to donors. The second experiment showed an effect of coumaphos persisting over time and appeared to be more sensitive than the first assay which measured only food consumption. Although there were no significant differences in mortality of recipients over $24 \mathrm{~h}$ when the donors were treated with $2 \mu \mathrm{g}$ prior to the experiment, significantly higher mortality was recorded after $4 \mathrm{~h}$.

In the application of Perizin for the treatment of varroosis, only $24 \%$ of the applied coumaphos reaches the alimentary canal of bees (van Buren et al. 1992b), and the bees initially taking up the drug receive comparatively higher doses (van Buren et al. 1993). If a bee ingests only $10 \mu \mathrm{L}$ of Perizin ${ }^{\circledR}$ solution, it receives $6.4 \mu \mathrm{g}$ of coumaphos, which exceeds the highest tested dose used in the present study. Our results could thus contribute to explaining why only a low amount of Perizin ${ }^{\circledR}$ solution is transferred between the colony members by means of trophallaxis (van Buren et al. 1992a). Theoretically after equal distribution among all colony members, the dosage per bee would be fairly low, suggesting rather negligible effects. Assuming that colonies in winter contain 16,000 bees (Crane 1990) and one treatment contains $32 \mathrm{mg}$ of coumaphos, each bee would potentially receive $2 \mu \mathrm{g}$ on average. Given that approximately one fourth of the coumaphos is ingested (van Buren et al. 1992b) and two treatments 1 week apart are recommended, a single bee would then receive in total $1 \mu \mathrm{g}$ which does not affect trophallaxis. Nevertheless, distribution of coumaphos among colony members is not equal (van Buren et al. 1993) and some bees receive higher doses.

Impaired trophallaxis could negatively affect foraging by inadequate nectar transfer and nursing which consequently would affect brood development. Foraging and dance communication could be affected directly by a decrease of trophallactic contacts between a dancer and followers, promoting and directing bees to forage (Farina and Wainselboim 2005). The possible negative impact on foraging suggests that coumaphos should be applied with great care, especially in summer when nectar flow is abundant.

The methods used in the study are robust and adequate for estimating the effectiveness of trophallaxis and could be a useful tool to test the effects of pesticides or other chemicals on the efficacy of trophallaxis under laboratory conditions. This approach assures that food had been actually transferred and may avoid potential misinterpretation of food transfer in behavioural assays recording trophallactic contacts since it has been shown that less than $5 \%$ of these interactions result in food transfer (Korst and Velthuis 1982). In addition, a transfer from a worker to another worker might last from a few seconds up to some minutes and, even if the attempt lasts more than $10 \mathrm{~s}$, it is not necessarily successful (Korst and Velthuis 1982). 


\section{ACKNOWLEDGEMENTS}

We thank Dr. Stefan Fuchs and Dr. Meta Virant Doberlet for their comments and Prof. Roger Pain for English revision. The study was funded by Slovenian Research Agency (grant no. 04040084).

Le coumaphos affecte la trophallaxie entre les ouvrières de l'abeille Apis mellifera.

\section{Apis mellifera / coumaphos / trophallaxie / comporte- ment social / nourriture}

Coumaphos beeinflusst die Übertragung von Futter zwischen Arbeiterinnen der Honigbiene Apis mellifera.

\section{Apis mellifera / Coumaphos / Trophallaxis / Sozial- verhalten / Futter}

Open Access This article is distributed under the terms of the Creative Commons Attribution Noncommercial License which permits any noncommercial use, distribution, and reproduction in any medium, provided the original author(s) and source are credited.

\section{REFERENCES}

Collins, A.M., Pettis, J.S., Wilbanks, R., Feldlaufer, M.F. (2004) Performance of honey bee (Apis mellifera) queens reared in beeswax cells impregnated with coumaphos. J. Apic. Res. 43, 128-143

Crailsheim, K. (1988) Regulation of food passage in the intestine of the honeybee (Apis mellifera L.). J. Insect Physiol. 34, 97-112

Crailsheim, K. (1998) Trophallactic interactions in the adult honeybee (Apis mellifera L.). Apidologie 29, 97-112

Crane, E. (1990) Bees and beekeeping: science, practice and world resources. Heinemann Newnes, Oxford

Farina, W.M., Wainselboim, A.J. (2005) Trophallaxis within the dancing context: a behavioural and thermographic analysis in honeybees (Apis mellifera). Apidologie 36, 43-47

Free, J.B. (1957) The transmission of food between worker honeybees. Br. J. Anim. Behav. 5, 41-47
Haarmann, T., Spivak, M., Weaver, D., Weaver, B., Glenn, T. (2002) Effects of fluvalinate and coumaphos on queen honey bees (Hymenoptera: Apidae) in two commercial queen rearing operations. J. Econ. Entom. 95, 28-35

Korst, P.J.A.M., Velthuis, H.H.W. (1982) The nature of trophallaxis in honeybees. Insectes Soc. 29, 209221

Menozzi, P., Shi, M.A., Lougarre, A., Tang, Z.H., Fournier, D. (2004) Mutations of acetylcholinesterase which confer insecticide resistance in Drosophila melanogaster populations, BMC Evolutionary Biology, [online] http://www.biomedcen.com/1471-2148/4/4 (accesed on 3 May 2010)

Moritz, R.F.A., Hallemen, M. (1986) Trophallaxis of worker honeybees (Apis mellifera L.). Insectes Soc. 33, 26-31

Pettis, J.S., Collins, A.M., Wilbanks, R., Feldlaufer, M.F. (2004) Effects of coumaphos on queen rearing in the honey bee, Apis mellifera. Apidologie 35, 605-610

Schneider, C., Bevk, D., Grünewald, B., Tautz, J., Fuchs, S. (2009) Radiofrequency identification. Apidologie 40, 659-660

Smodiš Škerl, M.I., Gregorc, A. (2010) Heat shock proteins and cell death in situ localisation in hypopharyngeal glands of honeybee (Apis mellifera carnica) workers after imidacloprid or coumaphos treatment. Apidologie 41, 73-86

van Buren, N.W.M., Mariën, A.G.H., Velthuis, H.H.W. (1992a) The role of trophallaxis in the distribution of Perizin in a honeybee colony with regard to the control of the Varroa mite. Entomol. Exp. App. 65, $157-164$

van Buren, N.W.M., Mariën, A.G.H., Oudejans, R.C.H. M., Velthuis, H.H.W. (1992b) Perizin, an acaricide to combat the mite Varroa jacobsoni: its distribution in and influence on the honeybee Apis mellifera. Physiol. Entomol. 17, 288-296

van Buren, N.W.M., Mariën, A.G.H., Velthuis, H.H.V. (1993) The effectiveness of systemic agents used to control the mite, Varroa jacobsoni, in colonies of the honeybee, Apis mellifera depends on food distribution patterns. Apidologie 24, 33-43

Tremolada, P., Bernardinelli, I., Colombo, M., Spreafico, M., Vighi, M. (2004) Coumaphos distribution in the hive ecosystem: case study for modeling applications. Ecotoxicology 13, 589-601 